\title{
Involvement of nuclear NHERF1 in colorectal cancer progression
}

\author{
ANITA MANGIA $^{1}$, CONCETTA SAPONARO $^{1}$, ANDREA MALFETTONE ${ }^{1}$, \\ DOMENICO BISCEGLIE ${ }^{1}$, ANTONIA BELLIZZI ${ }^{1}$, MARIACONSILIA ASSELTI ${ }^{2}$, ONDINA POPESCU ${ }^{2}$, \\ STEPHAN J. RESHKIN ${ }^{3}$, ANGELO PARADISO ${ }^{4}$ and GIOVANNI SIMONE ${ }^{2}$ \\ ${ }^{1}$ Functional Biomorphology Laboratory and ${ }^{2}$ Department of Pathology, National Cancer Centre, Bari; ${ }^{3}$ Department of General \\ and Environmental Physiology, University of Bari, Bari; ${ }^{4}$ Scientific Direction, National Cancer Centre, 70124 Bari, Italy
}

Received November 8, 2011; Accepted December 19, 2011

DOI: 10.3892/or.2012.1895

\begin{abstract}
NHERF1 $\left(\mathrm{Na}^{+} / \mathrm{H}^{+}\right.$exchanger regulatory factor 1$)$ is expressed in the luminal membrane of many epithelia, and associated with proteins involved in tumor progression. Alterations of NHERF1 expression in different sites of metastatic colorectal cancer (mCRC) suggest a dynamic role of this protein in colon carcinogenesis. We focused on the observation of the altered expression of NHERF1 from non-neoplastic tissues to metastatic sites by immunohistochemistry. Moreover, we studied, by immunofluorescence, the colocalization between NHERF1 and the epidermal growth factor receptor (EGFR), whose overexpression is implicated in CRC progression. NHERF1 showed a different localization and expression in the examined sites. The distant non-neoplastic tissues showed NHERF1 mostly expressed at the apical membrane, while in surrounding non-neoplastic tissue decreased the apical membrane and increased cytoplasmic immunoreactivity. In adenomas a shift from apical membrane to cytoplasmic localization and nuclear expression were observed. Cytoplasmic staining in the tumor, and metastatic sites was stronger than surrounding non-neoplastic tissue. Furthermore, nuclear NHERF1 expression was noted in $80 \%$ of all samples and surprisingly, it appeared already in adenoma lesions, suggesting that NHERF1 represents an early marker of pre-morphological triggering of colorectal carcinogenesis. Then, in few tumors a positive direct correla-
\end{abstract}

Correspondence to: Dr Anita Mangia, Functional Biomorphology Laboratory, National Cancer Centre, Viale Orazio Flacco 65, 70124 Bari, Italy

E-mail: a.mangia@oncologico.bari.it

Abbreviations: NHERF1, $\mathrm{Na}^{+} / \mathrm{H}^{+}$exchanger regulatory factor 1 ; mCRC, metastatic colorectal cancer; SNT, surrounding nonneoplastic tissue; DNT, distant non-neoplastic tissue; ADN, adenoma; T, primary tumor; LnM, synchronous lymph node metastasis; LM, liver metastasis; EGFR, epidermal growth factor receptor

Key words: metastatic colorectal cancer, carcinogenesis, immunohistochemistry tion between membrane NHERF1 and EGFR expression was evidenced by their colocalization. Nuclear NHERF1 expression, present in the early stages of carcinogenesis and related with poor prognosis, may contribute to the onset of malignant phenotype. Specifically, we hypothesize the direct involvement of nuclear NHERF1 in both carcinogenesis and progression and its role as a potential colorectal cancer marker.

\section{Introduction}

Colorectal cancer (CRC) is the second most common cause of cancer related death in the Western societies (1). At the time of diagnosis $19 \%$ of patients will present synchronous metastasis and $30-40 \%$ of patients will develop distant metachronous metastasis (2). The liver is one of the most common sites of metastasis and many molecular variables are still unclear. Some studies have suggested that the accumulation of specific alterations in cell growth genes are involved in cancer progression (3) and tumorigenesis (4). Thus, different gene expression can lead to unique transcriptional outcomes and consequently a multiple signalling pathways can be simultaneously activated. NHERF1 $\left(\mathrm{Na}^{+} / \mathrm{H}^{+}\right.$exchanger regulatory factor 1, also named EBP50) is an adaptor protein that links several cellular receptors, ion transporters and other proteins to the plasma membrane of different types of cells (5-9). The association between specific growth factor receptors and NHERF1 has already been analysed (8-10) and indicates a critical role for this adaptor protein in growth factor signal transduction. Recently in normal cells, the level of NHERF1 expression has been demonstrated to have effects on the trafficking, expression and function of the epidermal growth factor receptor (EGFR) (11). NHERF1 is a member of a family of scaffold proteins with two homologous PSD-95/Disc-large/ ZO-1 (PDZ) domains, which mediate protein-protein interactions (12) and an ERM (Ezrin/Radixin/Moesin) domain, with which it attaches to the cytoskeleton $(13,14)$. The PDZ1 domain interacts with the carboxyl-terminus of proteins (15), while the ERM domain binds to respective actin-associated ERM proteins (5). Proteins with PDZ domains are also present at the brush border of mammalian, intestine and renal proximal tubules $(16,17)$. The loss of heterozygosity $(\mathrm{LOH})$ at the NHERF1 gene locus (17q25.1) is present in more than 50\% of human breast tumors (18); whereas the LOH is less frequent 
in other tumor types, suggesting a pivotal role of NHERF1 during breast carcinogenesis (18). The NHERF1 protein is expressed in the luminal membrane of many epithelia and has been studied in many tumor types such as hepatocellular carcinoma (19) schwannoma (20) and particularly in breast cancer (21-23). Our previous studies showed that NHERF1 plays a role in breast cancer progression and it is able to induce an invasive phenotype in an 'in vitro' model of breast cancer (24-26). Moreover, we showed that breast carcinogenesis is characterized by increased cytoplasmic expression of NHERF1 as the tumor progresses. The switch from apical membrane to cytoplasmic expression is compatible with a dual role for NHERF1 as a tumor suppressor or tumor promoter dependent on its subcellular localization (10). Little is known about the involvement of NHERF1 in colorectal cancer. A recent study reported that NHERF1 alterations correlate with the progression and enhanced invasiveness of human colorectal cancer and that its loss or cytoplasmic overexpression is a common oncogenic event in carcinomas (26).

The aim of this study is to further clarify the role of NHERF1 in colorectal carcinogenesis and progression, examining the expression and the intracellular distribution of the protein in non-neoplastic tissues, adenomas, primary tumors and metastatic colorectal sites.

\section{Materials and methods}

Tissue samples. Formalin-fixed, paraffin-embedded sections from 51 metastatic colorectal carcinomas (mCRCs) were selected from the files of the Department of Pathology of our Institute. For each tumor the following histological sections were examined: primary tumor $(\mathrm{T})$ and surrounding nonneoplastic tissue (SNT) present on the same section, the corresponding synchronous lymph node (LnM) and liver metastases (LM). Distant non-neoplastic colorectal tissue (DNT) and adenomas (ADNs) obtained from 20 of the 51 tumors were also analyzed. The seventy five percent $(15 / 20)$ of ADNs, measured $<1 \mathrm{~cm}$, showed a high grade, while $41 \%$ $(11 / 20)$ of ADNs showed villousness $>20 \%$.

Histological sections were cut and stained with hematoxylin and eosin for light microscopic examination. Ethical approval of this study has been obtained from the Ethics Committee of our Institute. The pathological features of patients with these colorectal tumors were analysed by reviewing the histological sections of the surgical specimen. The colorectal tumors were graded and classified according to the World Health Organization (WHO) criteria (27).

The clinicopathological characteristics of patients are summarized in Table I. Thirty-one patients were male and 20 female with a mean age of 63 years (range, 44-85). Of all adenocarcinomas, 12 (24\%) cases showed low grade of differentiation and $39(76 \%)$ showed high grade of differentiation. Pathological staging was T3 in $67 \%(n=34)$ of cases and T4 in $33 \%(\mathrm{n}=17)$ of cases; lymph node status was $\mathrm{N} 1$ in $28 \%(\mathrm{n}=14)$ and $\mathrm{N} 2 / \mathrm{N} 3$ in $72 \%(n=37)$ of cases.

Immunohistochemistry. Tissue sections (4- $\mu \mathrm{m}$ thick) were deparaffinized with xylene, rehydrated in graded ethanol solutions, and in order to enhance antigen retrieval, the slides were then immersed in $10 \mathrm{mM}$ sodium citrate buffer ( $\mathrm{pH}$ 6.0), boiled
Table I. Clinicopathological characteristics of $51 \mathrm{mCRC}$ patients.

\begin{tabular}{lc}
\hline Characteristics & No. of patients (\%) \\
\hline Age (years), median (range) & $63(44-85)$ \\
$\leq 63$ & $26(51)$ \\
$>63$ & $25(49)$ \\
Gender & \\
Male & $31(61)$ \\
Female & $20(39)$ \\
Adenocarcinoma & $51(100)$ \\
Grade of differentiation & \\
Low & $12(24)$ \\
High & $39(76)$ \\
Pathological staging (pTNM) & \\
Tumor & \\
T3 & $34(67)$ \\
T4 & $17(33)$ \\
Node & \\
N1 & $14(28)$ \\
N2, N3 & $37(72)$ \\
Metastasis & \\
M1 & $51(100)$
\end{tabular}

for $30 \mathrm{~min}$ on a hot plate, and then allowed to cool for $20 \mathrm{~min}$. Sections were incubated for $10 \mathrm{~min}$ in $3 \%$ hydrogen peroxide in distilled water, washed in PBS three times for $5 \mathrm{~min}$. After, the sections were incubated overnight at $4^{\circ} \mathrm{C}$ with rabbit polyclonal anti-human EBP50 antibody (PA1-090 Affinity Bioreagents, Golden, CO; dilution 1:150). Sections were then washed with PBS, incubated with biotinylated link for $30 \mathrm{~min}$, peroxidase-labelled streptavidin for $30 \mathrm{~min}$, and 3-amino9-ethylcarbazole substrate-chromogen (LSAB2 System-HRP; DakoCytomation) for $15 \mathrm{~min}$ at dark. Counterstaining was done with hematoxylin. Immunohistochemical staining was evaluated as subcellular localization and classified as prevalently cytoplasmic, membrane or nuclear localization for each sample (10).

The extent and pattern of staining also varied among different tissues. NHERF1 expression was quantified by two independent observers by counting the positive cells in 3 representative areas for each section, recorded as percentage of stained cells/section and, the median value was used to form a final score. According to the median value cut-off, the cases were considered positive for cytoplasmic NHERF1 when immunoreactivity was present in $>70 \%$ of tumor cells examined, and positive for nuclear NHERF1 when completely and darkly nuclear staining was observed in $18 \%$ of tumor cells analysed. EGFR immunohistochemistry was performed according to the instructions included with the EGFR PharmDx kit (Dako Corp., Milan, Italy). For our study, 4- $\mu \mathrm{m}$ sections were deparaffinized in 2 sequential xylene baths, $100 \%$ ethanol, and $95 \%$ ethanol followed by a wash in wash-buffer solution (Dako). The rehydrated sections were pretreated in an 

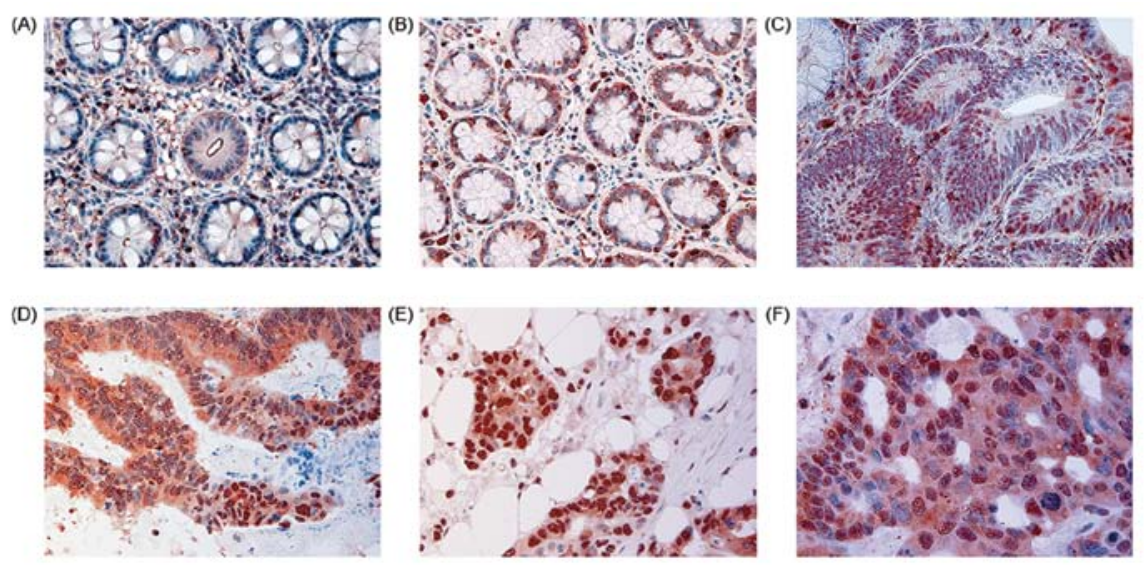

Figure 1. Progressive changes of NHERF1 expression levels and intracellular localization in mCRC. (A) NHERF1 immunoreactivity is present mostly in membrane of DNT mucosa, (B) in the cytoplasmic and nuclear compartments in SNT and (C) in ADN; (D) an increase of cytoplasmic and nuclear NHERF1 expression is present in T, (E) LnM and (F) LM (original magnification, $\mathrm{x} 200$ ).

enzyme solution (Proteinase-k) at room temperature for $5 \mathrm{~min}$. After the block of endogenous peroxidase activity, the sections were incubated with EGFR MoAb (IgG1, clone 2-18C9, Dako) for $30 \mathrm{~min}$, employing 3'3-diaminobenzidine as a chromogenic substrate. Sections were slightly counterstained with Mayer's hematoxylin and mounted in aqueous mounting medium (Glicergel, Dako). In each staining run, an external positive control section consisting of Dako control slide was used, and the negative control was performed by omitting the application of the primary antibody.

Immunoistochemical staining was evaluated by one of the authors (A.M.) together with an experienced pathologist (G.S.), and then discordant cases were reviewed in a joint evaluation. IHC scoring was based on the membrane immunoreactivity, according to the American Joint Committee (28): score 0, no reactivity; score $1+$, weak reactivity; score $2+$, moderate reactivity; score $3+$, strong reactivity. Cytoplasmic staining was considered non-specific and was not included in the scoring. The tumors overexpressing EGFR were scored mainly 3+ $(n=11), 2+(n=20)$ and $1+(n=6)$; those not overexpressing EGFR were scored $0(n=14)$. One of $2 \mathrm{LnM}$ and $2 / 3 \mathrm{LM}$ were scored $2+$, while those with negative EGFR were $1 \mathrm{LnM}$ and $1 \mathrm{LM}$.

Immunofluorescence of NHERF1/EGFR. Colocalization of membrane NHERF1 and EGFR was performed on 18 tumor specimens [13 showed moderate EGFR reactivity $(2+)$ and 5 showed strong reactivity (3+)], 1 metastatic lymph nodes, and 2 liver metastases assessed immunohistochemically. Immunofluorescence analyses were done as previously described (25). Briefly, serial sections of formalin-fixed tissue sections embedded in paraffin wax, 3- $\mu \mathrm{m}$ thickness, were obtained from the same colorectal tissue blocks used for immunohistochemistry. Rehydrated slides were immersed in a $10 \mathrm{mM}$ citrated buffer, $\mathrm{pH} 6.0$, at $95^{\circ} \mathrm{C}$ for $30 \mathrm{~min}$ for antigen retrieval and, prior to incubation with primary antibody, were treated for $10 \mathrm{~min}$ with $0.2 \%$ bovine serum albumin (BSA) to block non-specific protein binding. Primary antibodies were: mouse IgG anti-EGFR (clone 13/EGFR; 1:100 dilution) (BD Transduction Laboratories ${ }^{\mathrm{TM}}$ ) and rabbit IgG NHERF1 (PA1-
090; Affinity Bioreagents) (1:150 dilution). After, sections were incubated for $1 \mathrm{~h}$ with the Alexa Fluor 488 goat anti-mouse IgG1 and Alexa Fluor 568 goat anti-rabbit IgG secondary antibody conjugates (Molecular Probes, Eugene, OR, USA) (1:1000 dilution).

Images were acquired on a BX40 microscope (Olympus) with a SenSys 1401E-Photometrics charge-coupled device camera. Each fluorophore used was excited independently and sequential detection was performed and co-localization analysis was performed using the open source Image $\mathbf{J}$ version 1.38 (http://rsb.info.nih.gov/ij/).

Statistical analysis. The two-tailed non-parametric KruskalWallis and Mann-Whitney tests were used to compare the different expression levels of NHERF1 among different colorectal tissues. The association between NHERF1 and clinicopathological variables, and the correlation between membrane NHERF1 and EGFR were examined using $\chi^{2}$ test, and $\chi^{2}$ test for trend as appropriate. Statistical significance was calculated for a $95 \%$ confidence interval $(\mathrm{P}<0.05)$. Calculations were performed using Prism version 5.00 software package (GraphPad Software, San Diego, CA, USA).

\section{Results}

NHERF1 protein expression in metastatic colorectal cancer tissues. The DNT showed NHERF1 mostly expressed at the apical membrane (Fig. 1A). In those samples, median apical membrane expression was $15.0 \%$ (0-55 range of positive cells), whereas the median cytoplasmic staining was 5\% (0-60). In SNT, present on the same slide of the tumor, decreased apical membrane and increased cytoplasmic immunoreactivity of NHERF1 were observed (Fig. 1B). Apical membrane staining observed in those samples was $11.0 \%(0-48)$, while cytoplasmic staining was $10 \%(0-60)$.

In ADN, a different localization of NHERF1 was observed in both high and low grade ADNs (Fig. 1C). Median value of apical membrane expression was 2\% (0-40 range of positive cells), while median value of cytoplasmic staining was $57.5 \%$ (40-70). In T, NHERF1 expression showed a cyto- 

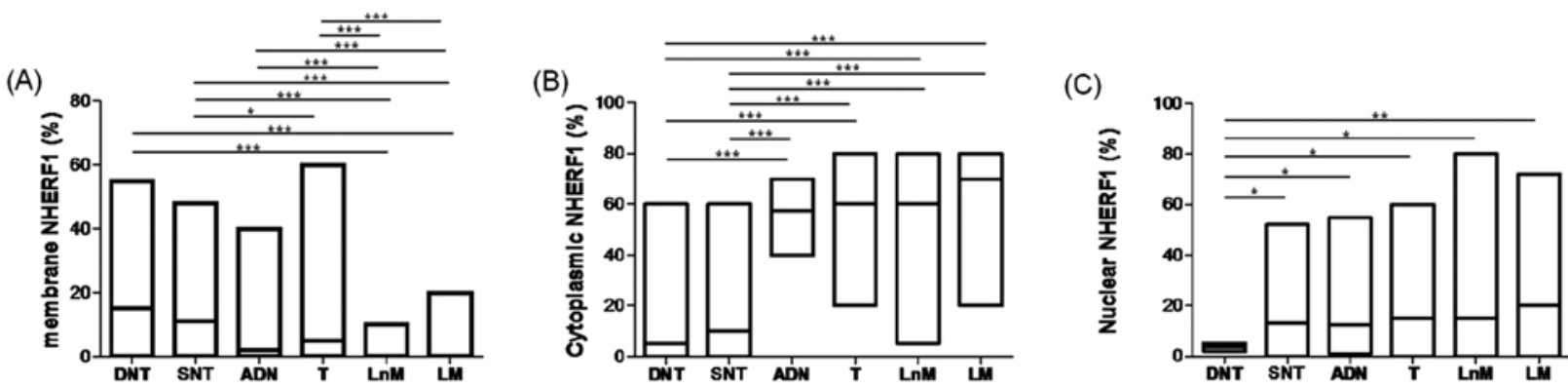

Figure 2. NHERF1 protein expression detected in the different colon cancer sites. (A) Membrane NHERF1 is more expressed in DNT and SNT than ADN, T LnM and LM. (B) The cytoplasmic NHERF1 increased significantly comparing the DNT to ADN, T, LnM and LM. (C) Nuclear NHERF1 in DNT showed a significant decrease respect to SNT, ADN, T, LnM and LM. ${ }^{*} \mathrm{p}<0.05 ;{ }^{* *} \mathrm{p}<0.001 ;{ }^{* * *} \mathrm{p}<0.0001$.
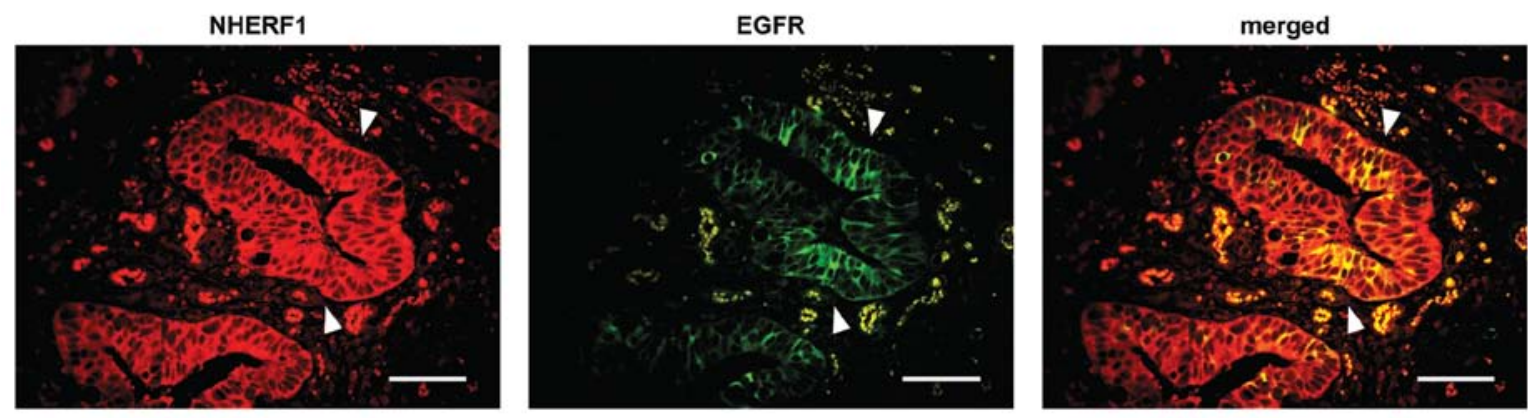

Figure 3. Analysis of NHERF1 and EGFR protein localization in colorectal cancer. A representative tissue sample stained with NHERF1 and EGFR antibodies and detected with Alexa Fluor 568 (red) and Alexa Fluor 488 (green) secondary antibodies, respectively, prior to fluorescence microscopy analysis Arrowheads indicate invasive cells with a high global expression of two proteins, where NHERF1 colocalized with EGFR1 on apical membrane compartment. Scale bar, $25 \mu \mathrm{m}$.

plasmic trend similar to ADN (Fig. 1D). The median value of cytoplasmic staining was $60 \%(20-80)$, whereas the median value of membrane staining was 5\% (0-60). In synchronous LnM (Fig. 1E) and LM (Fig. 1F), results similar to T were observed. LnM showed 60\% (5-80) of cytoplasmic staining and $0 \%(0-10)$ of membrane staining. Likewise, LM exhibited $70 \%(20-80)$ of cytoplasmic staining and $0 \%(0-20)$ membrane immunoreactivity.

As showed in Fig. 2A, membrane NHERF1 expression detected in LnM and LM showed a significant decrease with respect to DNT $(\mathrm{P}<0.0001)$. Moreover, membrane NHERF1 in $\mathrm{T}, \mathrm{LnM}$ and $\mathrm{LM}$ decreased significantly compared to SNT $(\mathrm{P}<0.0001)$. Finally, LnM and LM showed a decrease in membrane expression with respect to both ADN and T $(\mathrm{P}<0.0001)$.

The cytoplasmic staining of NHERF1 increased significantly comparing the DNT to ADN, T, LnM and LM, $(\mathrm{P}<0.0001$, for all). Moreover, in ADN, T, LnM and LM the immunoreactivity was more intense than observed in SNT ( $\mathrm{P}<0.0001$, for all) (Fig. 2B).

Nuclear NHERF1 expression was present in $80 \%$ $(154 / 193)$ of samples examined (Fig. 1A-F). We observed high and homogeneous nuclear expression in SNT, ADN, T, $\mathrm{LnM}$ and LM, with respect to DNT. Interestingly, DNT (3.5\%, range $2-5 \%$ ) showed a significantly lower nuclear expression than detected in NT (13.0\%, range 0-52), ADN $(12.5 \%$, range (1-55), T (15.0\%, range (0-60), and LnM (15.0\%, range 0-80) $(\mathrm{P}<0.05)$. However, the nuclear staining was more intense in LM (20.0\%, range 0-72) than in DNT (3.5\%, range 2-5) $(\mathrm{P}<0.001)$ (Fig. 2C). On the basis of a contingency analysis of $51 \mathrm{mCRC}$ cases, any statistically significant association between NHERF1 expression within the three compartments and clinicopathological characteristics was revealed (Table I).

Subcellular colocalization of NHERF1 with EGFR in $m C R C$ tissues. Of the tumors $45 \%$ (23/51) retained a low amount of NHERF1 in the membrane compartment, and $78 \%(18 / 23)$ of these cases showed overexpression of EGFR (score 2+/3+). On univariate analysis, positive membrane NHERF1 expression was statistically significantly associated with moderate EGFR immunostaining (score $2+)(13 / 23$ vs. $7 / 28, \mathrm{P}=0.035)$. To analyze the interaction between NHERF1 and EGFR, we examined their localization by immunofluorescence on tumor specimens, lymph node and liver metastatic tissues. In primary tumor and metastatic cells, NHERF1 showed its mostly cytoplasmic localization, together with large areas of NHERF1 nuclear localization, especially where cells became no longer polarized (Fig. 3). Noteworthy, in 45\% (23/51) of tumor cases, $4 \%(2 / 51)$ of lymph node and 5\% (3/51) of liver metastases, a low amount of NHERF1 was still localized in the membrane. At membrane compartment, NHERF1 colocalized with EGFR only when this receptor was overexpressed and showed strong or moderate reactivity (score $2+/ 3+$ ) (Fig. 3); in the cases with no EGFR reactivity (score 0), no membrane NHERF1 expression was observed. 


\section{Discussion}

NHERF1 is an adaptor protein frequently expressed in different human cancers. It is associated with $\beta$-catenin through its PDZ2 domain (19) and consequently involved in cancer progression.

In this study, we focused on the observation of expression and subcellular localization of NHERF1 to evaluate its involvement in different sites of metastatic colorectal cancer. Differently to a previous study (26), here we assessed a more wide and homogeneous series of human CRC and metastatic sites composed of non-neoplastic tissue, adenoma, primary tumor, and synchronous lymph node and liver metastases. Our results confirm the presence of NHERF1 at the apical membrane of epithelial cells in DNTs $(10,23)$. However, biological difference of NHERF1 expression among different tissues is present and can be associated at the adenoma-carcinoma sequence (26). The SNT, present on the same section of the tumor area, showed a persistence of apical membrane NHERF1 expression, more intense than in tumor and metastatic sites. However, here we observed the increasing of cytoplasmic and nuclear staining, demonstrating the rapid biochemical changes respect to morphological evidence during the tumor development. This would suggest a strong influence of the tumor on its SNT, and the loss of membrane NHERF1 expression could be compatible with onset of an aggressive phenotype (26). Results obtained by this study indicate that NHERF1 represents an early marker of pre-morphological triggering of carcinogenesis.

Even if the analyzed ADNs were few and not evenly distributed, in both low and high grade adenomas, we already observed a shift from apical membrane to cytoplasmic and nuclear expression, suggesting the involvement of NHERF1 in first steps of the pre-malignant lesions. In fact, the increase of cytoplasmic and nuclear NHERF1 expression suggests a possible direct interaction between NHERF1 and $\beta$-catenin, setting up Wnt/ $\beta$-catenin pathway and consequently the cancer progression (19). Comparing the SNT with other tumor sites we observed a greater percentage of cytoplasmic staining in the $\mathrm{T}$, and in both LnM and LM. This change in cytoplasmic protein expression has been described previously by Hayashi et al regarding adenomas and 'in vitro' models (26). In NHERF1depleted cells, the ectopically expressed wt-NHERF1 was distributed in the cytoplasm with a concomitant reduction in epithelial morphology and increased cell proliferation. These results support our previous study that described a significant change in subcellular distribution of NHERF1 moving from breast non-neoplastic tissue to carcinoma (10). Consequently, the elevated cell proliferation in tumor area could be a consequence of higher cytoplasmic NHERF1 expression in tumor compared to SNT. This would rely on the direct interaction between NHERF1 and $\beta$-catenin, with further activation of the Wnt/ $\beta$-catenin pathway, as previously demonstrated (26).

Furthermore, nuclear NHERF1 expression was reported previously in hepatocellular carcinoma (19) and in breast cancer (10). Shibata et al underlined that NHERF1 interacts with $\beta$-catenin through its PDZ2 domain, establishing a complex formation in hepatocellular carcinoma model (19). In the current study we found nuclear NHERF1 expression in $80 \%$ of the colon samples analyzed and surprisingly, nuclear expression appeared already in SNT and ADN lesions, but not in DNT samples. Our findings indicated that there are significant changes in the expression of the nuclear NHERF1 in colorectal adenocarcinoma and adenoma in comparison to non-neoplastic tissue. This implies that nuclear NHERF1 is involved in the pathogenesis of colorectal tumors, opening a new undiscovered and challenging role for NHERF1 as a player in carcinoma progression. Nuclear NHERF1 could collaborate at initiation and maintaining the tumor phenotype, possibly by associating with $\beta$-catenin. Based on these findings and those of other studies, NHERF1 would act as a tumor suppressor when localized at the apical level of the membrane and as an oncogenic protein when localized in the cytoplasm and nucleus $(10,29,30)$.

Moreover, as a scaffolding protein, NHERF1 is associated with a number of growth factor TK receptors, such as the Her2/ neu (10) and the EGFR (31), promoting dimerization and activation of mitogenic signals. The downregulation in metastases has recently been indicated also in other previously published studies (32-34). EGFR overexpression has been found to be associated with tumor progression and poor survival in several tumor types, such as in CRC (35), and importantly, our results underlined the involvement of NHERF1 along with EGFR in the CRC progression.

Previously, it has been reported that NHERF1 and EGFR colocalized at the cell membrane of colon cancer tissues (30). In this study, we observed that in a small percentage of tumors NHERF1 maintained a membrane localization and a positive direct correlation between membrane NHERF1 and EGFR expression was evidenced by their colocalization. The CRC cell architecture is completely overturned and cells are able to receive different extracellular signals from the tumor microenvironment; in this pathological state NHERF1, having lost its exclusively apical domain function, is overexpressed in the cytoplasm and nucleus and starts to coordinate intracellular cancer pathways. These data reiterate that NHERF1 alterations correlate with progression and enhanced invasiveness of human colorectal cancer.

In conclusion, nuclear NHERF1 expression showed a heterogeneous distribution in the different colon sites, from non-neoplastic tissue to carcinoma and metastases. It confirms a dynamic role of the protein in colorectal cancer, not only as physiological scaffolding protein. In particular, the nuclear NHERF1 expression, present in the early stages of carcinogenesis, probably contributes to onset of the malignant phenotype. Thus, we hypothesize the direct involvement of nuclear NHERF1 in both carcinogenesis and progression of colorectal cancer.

\section{Acknowledgements}

A.A. would like to thank Rossana Daprile for technical help. S.J.R. would like to thank the Italian Association for Cancer Research (AIRC) grant no. 5167 and the PIO grant no. 3 for supporting this study.

\section{References}

1. Jemal A, Siegel R, Ward E, Hao Y, Xu J, Murray T and Thun MJ: Cancer statistics. CA Cancer J Clin 58: 71-96, 2008. 
2. Horner MJ, Ries LAG, Krapcho M, et al: SEER cancer statistics review, 1975-2006. Bethesda, MD: National Cancer Institute; http://seercancergov/csr/1975-2006/; 2009.

3. Fearon ER and Vogelstein B: A genetic model for colorectal tumorigenesis. Cell 1: 759-767, 1990.

4. Sjöblom T, Jones S, Wood LD, et al: The consensus coding sequences of human breast and colorectal cancers. Science 13: 268-274, 2006

5. Bretscher A, Chambers D, Nguyen R and Reczek D: ERM-Merlin and EBP50 protein families in plasma membrane organization and function. Annu Rev Cell Dev Biol 16: 113-143, 2000.

6. Voltz JW, Weinman EJ and Shenolikar S: Expanding the role of NHERF, a PDZ-domain containing protein adapter, to growth regulation. Oncogene 20: 6309-6314, 2001.

7. Mahon MJ, Donowitz M, Yun CC and Segre GV: $\mathrm{Na}(+) / \mathrm{H}(+)$ exchanger regulatory factor 2 directs parathyroid hormone 1 receptor signalling. Nature 20: 858-861, 2002.

8. Shenolikar S, Voltz JW, Cunningham R and Weinman EJ: Regulation of ion transport by the NHERF family of PDZ proteins. Physiology 19: 362-369, 2004.

9. Weinman EJ, Hall RA, Friedman PA, Liu-Chen LY and Shenolikar S: The association of NHERF adaptor proteins with g protein-coupled receptors and receptor tyrosine kinases. Annu Rev Physiol 68: 491-505, 2006.

10. Mangia A, Chiriatti A, Bellizzi A, Malfettone A, Stea B, Zito FA, Reshkin SJ, Simone G and Paradiso A: Biological role of NHERF1 protein expression in breast cancer. Histopathology 55: 600-608, 2009.

11. Curto M, Cole BK, Lallemand D, Liu CH and McClatchey AI: Contact-dependent inhibition of EGFR signaling by Nf2/Merlin. J Cell Biol 5: 893-903, 2007.

12. Fanning AS and Anderson JM: PDZ domains: fundamental building blocks in the organization of protein complexes at the plasma membrane. J Clin Invest 103: 767-772, 1999.

13. Reczek D, Berryman M and Bretscher A: Identification of EBP50: A PDZ-containing phosphoprotein that associates with members of the ezrin-radixin-moesin family. J Cell Biol 6 : 169-179, 1997.

14. Louvet-Vallée S: ERM proteins: from cellular architecture to cell signalling. Biol Cell 92: 305-316, 2000.

15. Mahon MJ and Segre GV: Stimulation by parathyroid hormone of a NHERF-1-assembled complex consisting of the parathyroid hormone I receptor, phospholipase Cbeta, and actin increases intracellular calcium in opossum kidney cells. J Biol Chem 28 : 23550-23558, 2004

16. Fouassier L, Duan CY, Feranchak AP, et al: Ezrin-radixinmoesin-binding phosphoprotein 50 is expressed at the apical membrane of rat liver epithelia. Hepatology 33: 166-176, 2001.

17. Donowitz M, Cha B, Zachos NC, Brett CL, Sharma A, Tse CM and Li X: NHERF family and NHE3 regulation. J Physiol 567 3-11, 2005 .

18. Pan Y, Wang L and Dai JL: Suppression of breast cancer cell growth by $\mathrm{Na}^{+} / \mathrm{H}^{+}$exchanger regulatory factor 1 (NHERF1). Breast Cancer Res 8: R63, 2006.

19. Shibata T, Chuma M, Kokubu A, SakamotoM and Hirohashi S: EBP50, a beta-catenin associating protein, enhances Wnt signaling and is overexpressed in hepatocellular carcinoma. Hepatology 38: 178-186, 2003.

20. Fraenzer JT, Pan H, Minimo L Jr, Smith GM, Knauer D and Hung G: Overexpression of the NF2 gene inhibits schwannoma cell proliferation through promoting PDGFR degradation. Int J Oncol 24: 1493-1500, 2003.
21. Stemmer-Rachamimov AO, Wiederhold T, Nielsen GP, et al: NHE-RF, a merlin-interacting protein, is primarily expressed in luminal epithelia, proliferative endometrium, and estrogen receptor-positive breast carcinomas. Am J Pathol 158: 57-62, 2001.

22. Song J, Bai J, Yang W, Gabrielson EW, Chan DW and Zhang Z: Expression and clinicopathological significance of oestrogenresponsive ezrin-radixin-moesin-binding phosphoprotein 50 in breast cancer. Histopathology 51: 40-53, 2007.

23. Georgescu MM, Morales FC, Molina JR and Hayashi Y: Roles of NHERF1/EBP50 in cancer. Curr Mol Med 8: 459-468, 2008.

24. Cardone RA, Bagorda A, Bellizzi A, Busco G, Guerra L, Paradiso A, Casavola V, Zaccolo M and Reshkin SJ: Protein kinase A gating of a pseudopodial-located RhoA/ROCK/p38/ NHE1 signal module regulates invasion in breast cancer cell lines. Mol Biol Cell 16: 3117-3127, 2005.

25. Cardone RA, Bellizzi A, Busco G, Weinman EJ, Dell'Aquila ME, Casavola V, Azzariti A, Mangia A, Paradiso A and Reshkin SJ: The NHERF1 PDZ2 domain regulates PKA-RhoA-p38-mediated NHE1 activation and invasion in breast tumor cells. Mol Biol Cell 18: 1768-1480, 2007.

26. Hayashi Y, Molina JR, Hamilton SR and Georgescu MM: NHERF1/EBP50 is a new marker in colorectal cancer. Neoplasia 12: 1013-1022, 2010

27. Hamilton, SR, Vogelstein, B, Kudo S, Riboli E, Nakamura S and Hainaut P: Carcinoma of the colon and rectum. In: WHO Classification of Tumors: Pathology and Genetics of Tumors of Digestive System. Hamilton SR and Aaltonen LA (eds). IARC Press, Lyon, France, pp105-119, 2000.

28. Goldstein NS, Armin M: Epidermal growth factor receptor immunohistochemical reactivity in patients with American Joint Committee on Cancer Stage IV colon adenocarcinoma: implications for a standardized scoring system. Cancer 92: 1331-1346, 2001.

29. Takahashi Y, Morales FC, Kreimann EL and Georgescu MM: PTEN tumor suppressor associates with NHERF proteins to attenuate PDGF receptor signalling. EMBO J 5: 910-920, 2006.

30. Kreimann EL, Morales FC, de Orbeta-Cruz J, Takahashi Y, Adams H, Liu TJ, McCrea PD and Georgescu MM: Cortical stabilization of beta-catenin contributes to NHERF1/EBP50 tumor suppressor function. Oncogene 26: 5290-5299, 2007.

31. Lazar CS, Cresson CM, Lauffenburger DA and Gill GN: The $\mathrm{Na}^{+} / \mathrm{H}^{+}$exchanger regulatory factor stabilizes epidermal growth factor receptors at the cell surface. Mol Biol Cell 15: 5470-5480, 2004.

32. Wei Q, Shui Y, Zheng S, Wester K, Nordgren H, Nygren P, Glimelius B and Carlsson J: EGFR, HER2 and HER3 expression in primary colorectal carcinomas and corresponding metastases: implications for targeted radionuclide therapy. Oncol Rep 25: 3-11, 2011.

33. Ljuslinder I, Malmer B, Isaksson-Mettävainio M, Oberg A, Henriksson R, Stenling R and Palmqvist R: ErbB 1-4 expression alterations in primary colorectal cancers and their corresponding metastases. Anticancer Res 29: 1489-1494, 2009.

34. Scartozzi M, Bearzi I, Berardi R, Mandolesi A, Pierantoni C and Cascinu S: Epidermal growth factor receptor (EGFR) downstream signalling pathway in primary colorectal tumours and related metastatic sites: optimising EGFR-targeted treatment options. Br J Cancer 97: 92-97, 2007.

35. Krasinskas AM: EGFR signaling in colorectal carcinoma. Patholog Res Int: 932932, 2011. 